\title{
Second Opinion Assessment in Diagnostic Mammography at a Breast Cancer Centre
}

\section{Zweitbefundung in der kurativen Mammadiagnostik an einem Brustzentrum}

Authors

Affiliations
J. Lorenzen ${ }^{1}$, A. K. Finck-Wedel ${ }^{1}$, B. Lisboa ${ }^{2}$, G. Adam ${ }^{1,3}$

${ }^{1}$ Klinik und Poliklinik für Diagnostische und Interventionelle Radiologie, Universitätsklinik Hamburg-Eppendorf, Hamburg, Germany

${ }^{2}$ Klinik und Poliklinik für Gynäkologie, Universitätsklinik Hamburg-Eppendorf, Hamburg, Germany

${ }^{3}$ Universitätsklinik Hamburg-Eppendorf, Hamburg, Germany

\section{Key words \\ - breast neoplasm \\ - quality assurance \\ - second opinion \\ - BI-RADS \\ Schlüsselwörter \\ - Brusttumore \\ - Qualitätssicherung \\ - Zweitbefundung \\ - BI-RADS}

received 12.10.2011 revised 22.4.2012 accepted 19.5.2012

\section{Bibliography}

Dol http://dx.doi.org/ 10.1055/s-0032-1315107 Geburtsh Frauenheilk 2012; 72: 734-739 @ Georg Thieme Verlag KG Stuttgart · New York . ISSN 0016-5751

Correspondence
Dr. Jörn Lorenzen
Universitätsklinik
Hamburg-Eppendorf
Klinik und Poliklinik
für Diagnostische und
Interventionelle Radiologie
Hamburg
lorenzen@uke.uni-hamburg.de

\section{Abstract}

$\nabla$

Purpose: The aim of this retrospective study was to evaluate the importance of second opinion assessment for diagnostic mammography and sonography in a breast cancer centre.

Material and Method: We analysed a total of 374 diagnostic mammographies and sonographies. All patients had previously undergone mammography and sonography examination in different external clinics, and the findings had been classified according to the BI-RADS system. All patients underwent additional sonography investigation in the outpatient department of our university clinic with additional mammography where necessary. The final diagnosis (histological clarification in 316 cases, follow-up in 58 cases) was compared with the BI-RADS classification made by the external clinics and by the university clinic, and the correlation between their findings and the final diagnosis was analysed.

Results: The final diagnosis yielded 146 benign lesions and 228 cancers. In $74 \%$ of cases (277) $374)$, the BI-RADS classification of the first assessment corresponded to that of the second assessment. 26/55 lesions (47\%) were upgraded at the second assessment from BI-RADS 3 to BI-RADS 4, and 71/186 findings (38\%) were downgraded at the second assessment from BI-RADS 4 to BIRADS 3. The correlation between the initial diagnosis made in the external facilities and the final diagnosis was low (kappa: 0.263 ), but the correlation between the second opinion assessment and the final diagnosis was significantly $(p<0.001)$ higher (kappa: 0.765). The second assessment increased the sensitivity from $91 \%$ (208/228) to $99 \%$ $(225 / 228)$ and the specificity from $32 \%(46 / 146)$ to $74 \%(108 / 146)$. 20 additional malignant lesions were only detected at the second assessment; however the second assessment also resulted in

\section{Zusammenfassung \\ $\nabla$}

Ziel: Ziel dieser retrospektiven Studie war es, die Bedeutung der Zweitbefundung bei der kurativen Mammadiagnostik für die Patientinnen in einem Brustzentrum zu evaluieren.

Material und Methode: Wir untersuchten 374 diagnostische Mammografien und Sonografien. Alle Patientinnen hatten bereits in auswärtigen Praxen eine Mammografie und Sonografie erhalten und waren nach dem BI-RADS-System eingestuft worden. Ergänzend wurden bei allen Patientinnen in der Ambulanz der Universitätsklinik eine Sonografie und bei Bedarf ergänzende mammografische Aufnahmen durchgeführt. Die endgültige Diagnose (Histologie in 316 Fällen, Verlaufskontrolle bei 58 Frauen) wurde mit der BIRADS-Einstufung der Praxis und der Klinik verglichen und die Korrelation mit dem endgültigen klinischen Ergebnis analysiert.

Ergebnisse: Insgesamt wurden 146 benigne Läsionen und 228 Karzinome nachgewiesen. Eine Übereinstimmung der BI-RADS-Einschätzung zwischen Erst- und Zweitbefundung wurde in 74\% der Fälle (277/374) nachgewiesen. 26/55 Läsionen $(47 \%)$ wurden von BI-RADS 3 durch die Zweitbefundung nach BI-RADS 4 hochgestuft und 71/186 Befunde (38\%) durch die Zweitbefundung von BI-RADS 4 nach BI-RADS 3 abgestuft. Die Übereinstimmung zwischen der auswärtigen Erstbefundung und der endgültigen Diagnose erreichte nur eine niedrige Korrelation (kappa: 0,263), die aber durch die Zweitbefundung signifikant $(p<0,001)$ gesteigert werden konnte (kappa: 0,765). Die Sensitivität konnte durch die Zweitbefundung von 91\% (208/228) auf 99\% (225/228) angehoben werden und die Spezifität von 32\% (46/146) auf 74\% (108/146). Durch die Zweitbefundung wurden 20 Karzinome zusätzlich nachgewiesen, allerdings wurden auch 
3 additional false-negative findings. Surgical biopsy was prevented in 49 women after the second assessment.

Conclusion: An independent second diagnostic evaluation can significantly improve the correlation between BI-RADS classification and the final diagnosis, resulting in a benefit for the patient.

\section{Introduction}

$\nabla$

With the introduction of certified breast centres in Germany, preoperative second opinion assessment and preoperative workup has become an important area for radiologists working in breast centres. The aim is to keep the proportion of operated malignant findings at least twice as high as the proportion of benign findings. Second opinion investigations to the benefit of patients have only rarely been carried out in breast centres, although the personnel and equipment costs are not insignificant. Obtaining a second opinion, either from an independent radiologist blinded to the original findings or from a radiologist aware of the primary findings is an established and mandatory procedure in breast cancer screening. Independent second opinion assessments have been found to increase the sensitivity by up to $15 \%[1,2]$. However, a second opinion assessment done in a breast centre differs from the procedure for breast cancer screening. In the former case, the findings of the first investigator are known and the second opinion is therefore not independent but a second assessment of the primary findings.

In the European guidelines and in the S3 guidelines for breast cancer screening in Germany, obtaining a second opinion in cases classified as BI-RADS 3, 4 and 5 is mandatory, and in the European guidelines it is also recommended in cases classified as BIRADS 1 and $2[3,4]$. The additional use of sonography is also stipulated in cases classified as BI-RADS 4 and 5, in cases where the palpation findings are abnormal and for clinically occult mammographic findings $[5,6]$. The results of the diagnostic procedures are then documented using the BI-RADS system to ensure that the findings comply with quality assurance standards and to allow study results to be compared [7-10,11].

These results are now available for breast cancer screening [12, 13]. However, the age group of patients aged 50-69 years covers only $55 \%$ of all cases of breast cancer and does not incorporate the rates for participants who took part in screening or rates for carcinomas which developed in the period between a negative screening and the next regular screening.

The certified breast centres which have been and are being set up in Germany will therefore also have the task of documenting the results of second opinion investigations and of making these results available to the physicians referring these patients for quality assurance purposes.

As part of such quality assurance measures, this study aims to analyse the extent of agreement between second opinion assessments and histological results compared to primary findings at a breast centre of a university clinic.
3 falsch negative Umstufungen vorgenommen. Bei 49 Frauen konnte eine Operation durch die Zweitbefundung vermieden werden.

Schlussfolgerung: Die unabhängige Zweitbefundung führt zu einer signifikanten Verbesserung der Übereinstimmung zwischen der diagnostischen Einschätzung und dem klinischen Ergebnis und einem Benefit für die Patientinnen.

\section{Material and Methods}

\section{V}

\section{Patients}

Around 5000 women attend the breast screening clinic of the outpatient department of the university radiology clinic Hamburg-Eppendorf each year. In addition to screening patients with a familial risk of breast cancer and following up women with breast cancer, women with an external diagnosis of breast cancer are also examined. These are women who have already presented to the breast clinic of the Gynaecological Hospital with an indication for surgery or punch biopsy and women with diagnostic or clinical abnormalities referred to us for a second outpatient breast assessment by external physicians or at their own request. Primary selection of appropriate patients was done using the radiology information system (RIS) and the search term "external mammography images". This term was used to record all second opinion assessments done in the breast centre, as this is the term always used to document an assessment of images made in external facilities when recording the services provided in the choice box of the RIS. This term did not cover patients who only presented to the breast centre based on previous sonography findings. Such patients were therefore not included in the study. Patients where the services provided were not correctly recorded in the RIS were also not included, anyhow the percentage of such patients in our target collective is likely to have been less than $5 \%$.

The following inclusion criteria were used to select patients for inclusion in this study:

1. Written documented external findings with a conclusive BI-RADS classification.

2. External mammography and sonography screening was done by the same investigator.

3. Patients who underwent additional investigations such as MR mammography, the findings of which were incorporated in the final diagnosis made by our breast clinic were excluded to ensure a better comparability of the second opinion assessments with the external classifications. Additional mammography images such as magnifications done during the second opinion assessment were, however, considered admissible.

The period selected for this retrospective study which was approved by the local ethics committee covered all assessments made between January 2001 and July 2003. This ensured a sufficiently long follow-up time (6.8-8.6 years, mean 7.3 years) for findings which were not subject to a final histological clarification, i.e. particularly microcalcifications. Out of 380 women included in the study, 6 women were lost to follow-up so that in the end a total of 374 women (mean age 57 years, range 23-99 years) were included in the study.

Patients of this patient collective who presented to the university clinic for a second opinion assessment either had abnormal sonography and/or mammography findings with an indication for punch biopsy or surgical intervention (308 patients, BI-RADS 45 ) or had been classified as requiring close diagnostic follow-up 
(66 patients, BI-RADS 3). Other patients included women with abnormal clinical findings (palpation: 6 patients, mastodynia: 3 patients, mastitis 1 patient) and women with normal findings according to the assessment of external investigators (11 patients, BI-RADS 1).

\section{Second assessment procedure}

When the patients presented to the outpatient department of the university radiology clinic, the first step consisted of reviewing the existing documents and the mammography and sonography images. Following this, the investigator talked with the patient and a second investigation (palpation) was done together with additional mammography where necessary, e.g., targeted mammogram and magnification of images (Mammo-Diagnost 3000, Philips, Best, Netherlands). An additional sonographic investigation was always done using 7.5-10 MHz linear transducers (AU4 Idea, Esaote GmbH, Munich, Germany; Sonoline Sienna, Siemens AG, Erlangen, Germany). The sonographic investigation was always done with full knowledge of the external findings and of the mammography by the same investigator.

The findings were recorded on an evaluation sheet and included information on the patient's history (previous breast disease, operations, hormone therapy, familial history) and the clinical findings (palpation findings, mastodynia, findings of previous palpation investigation).

Investigations were done by a specialist for diagnostic radiology with at least 1 year full-time experience working in breast diagnostics in the outpatient department of the university clinic. The existing mammograms and sonography images were assessed by a 2nd specialist (at least 3 years full-time experience as a radiologist), and the final opinion was consensual. The results together with the assessment and recommendations for the further course of action were recorded in writing on the same day in the radiology department prior to any histological clarification (e.g. punch biopsy). The further course of action was subsequently agreed upon or modified in a discussion with the patient and, where indicated, with colleagues from the interdisciplinary breast clinic (gynaecology/radiology) and the referring physicians. Patients with histologically benign or normal findings at punch biopsy were followed up at the outpatient department at an interval of 6 months and 1 year.

\section{Data collection and data analysis}

The following data were collected based on the patient's health records: indication based on external examination, investigations done at external facilities and in the breast centre, type of lesion (microcalcification, focus, architectural distortion). The size of the lesion was recorded based on the findings in the second opinion assessment. For findings which could be circumscribed using both investigation methods, the largest measured dimensions were used for assessment. Both the external assessment and our own assessment included an overall assessment of the additional mammography and sonography findings with classification into BI-RADS categories in accordance with the inclusion criteria.

For this study, the separate diagnostic assessments of mammography and sonography images were retrospectively classified either as category 1-3 (normal, benign, or follow-up required) or category 4-5 (requires histological clarification) based on the written description of findings, as no explicit BI-RADS classification was used to categorise sonography images during the investigation period. The evaluation of the results of the study was done retrospectively using the written findings recorded in the clinic's radiological information system by an evaluator not involved in the second assessment. Only written findings recorded prior to the result of punch biopsy were used for this.

The respective assessments of findings were compared with the results of histological workup or follow-up visits. Patient followup was evaluated using the RIS. Patients who were not followed up at the university breast clinic were contacted in writing or by telephone and their further course was recorded.

\section{Statistical evaluation}

Patients were assigned to one of 2 groups for evaluation: either no suspicion of cancer (BI-RADS 1-3), or suspicious for cancer (BI-RADS 4-5). The suspicion of cancer was based on at least one diagnostic procedure (mammography/sonosgraphy) for the assessment to be classified as true-positive (histologically malignant finding) or false-positive (histologically benign or normal finding). These data were then used to calculate the rate of falsepositive and false-negative findings for both the external assessment and the second opinion assessment.

Cohen's kappa index was used to express the extent of concordance between the BI-RADS classification of the first and of the second assessment and the final diagnosis, and calculations were done using the SPSS statistics programme (Statistical Package for the Social Sciences) [14]. Interpretation of the kappa values was done using the categories of Landis und Koch: 0.0-0.2 poor; 0.21-0.4 fair; $0.41-0.6$ moderate; $0.61-0.8$ good; $0.81-1.0$ very good [15].

The sensitivity, specificity, and the positive and negative predictive value were calculated separately for the first and second assessment.

\section{Results}

\section{Histology and tumour stages}

Histological verification of findings was done within 2 weeks either by surgical intervention or punch biopsy in 316/374 patients (84\%); 58 cases (16\%) were followed up. A malignancy was found in $228 / 374$ patients (61\%). Histology showed benign findings in 88 patients and 58 patients were followed up with no abnormalities found during follow-up.

156 of 200 invasive carcinomas were tumour stage T1 (78\%) and 44 were tumour stage T2 (22\%). No higher grade tumour lesions were found.

The most common mammography findings with a total of 245 lesions (66\%) were focal findings with or without microcalcifications, followed by solitary microcalcifications in 78 cases (21\%), and parenchymal asymmetries or architectural distortion in 22 patients (6\%). 27 lesions (7\%) were only visible as focal findings on sonography. In two cases, the mammogram and sonography were normal ( Table 2 ).

\section{BI-RADS classification of findings}

The BI-RADS classifications of lesions in the first and second assessment are shown in $\bullet$ Fig. $\mathbf{1}$, and $\bullet$ Table 1 shows the number of true and false assessments of findings. A concordance between the first and the second diagnostic assessment was found in $74 \%$ (277/374) of cases.

The biggest differences in the assessment of findings between the first and the second assessment were found, as we expected, for the BI-RADS categories 3 and 4. Twenty-six of 55 patients (47\%) 


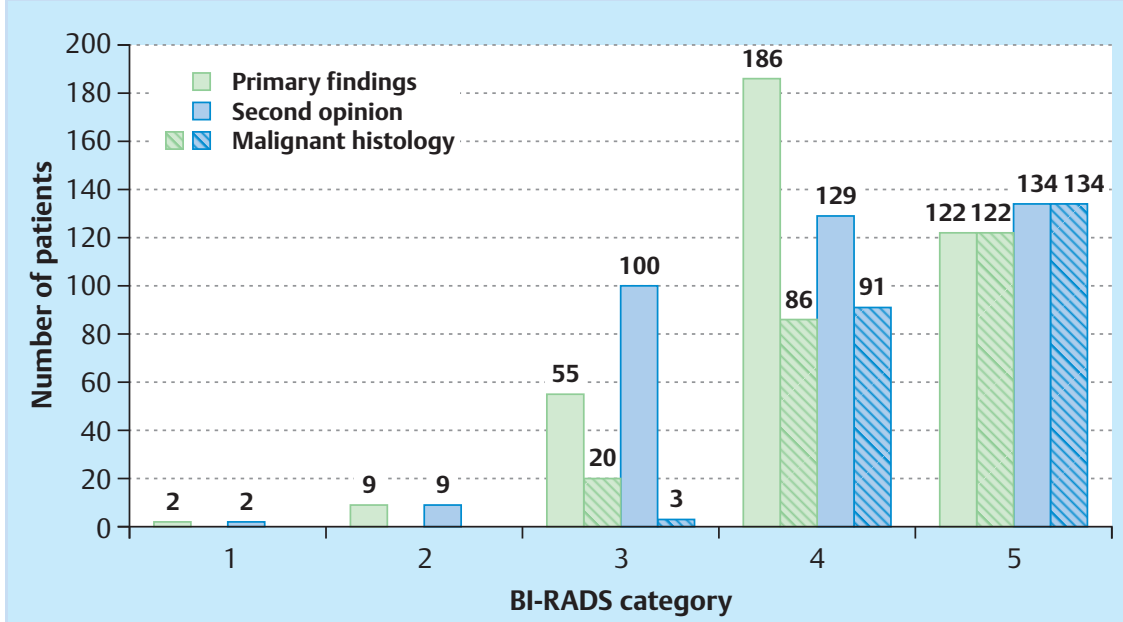

Fig. 1 Distribution of BI-RADS classifications in the first assessment (green bar) and the second assessment (blue bar) and respective numbers of malignant findings (hatched).

B-RADS category

were reclassified at the second assessment from BI-RADS 3 to BIRADS 4 and, conversely, 71/186 of patients (38\%) were reclassified in the second opinion assessment from suspected malignancy (BI-RADS 4) in the first assessment to BI-RADS 3 (probably benign) ( $\bullet$ Fig. 1 ).

In the first assessment, 91\% (208/228) of lesions classified as BIRADS 4 and 5 were true-positive and 46 lesions were true-negative (Table 1). $27 \%$ (100/372) of the lesions assessed for the first diagnosis were found to be false-positive. Of the false-positive cases, the most commonly misinterpreted lesions were asymmetries and architectural distortion in mammograms and microcalcifications ( $\bullet$ Table 2). Overall, the first assessment had a sensitivity of $91 \%$ and a specificity of $32 \%$ ( Table 3 ).

In the second assessment, 225 of the 228 malignant lesions were classified as suspicious (sensitivity: 99\%) and 108 of 146 benign findings were correctly assessed (specificity 74\%). In 37 cases, a suspicious finding was noted during the second assessment, which could subsequently not be verified histologically or during follow-up ( Table 1). Among the false-positive findings, sonographic findings, asymmetries and architectural distortion predominated. Of the 111 lesions classified as benign in the second assessment, 3 findings were false-negative.

When the concordance between diagnostic assessment and histology or follow-up was calculated, the first assessment had a kappa value of 0.263 , which corresponds to a fair correlation, while the second assessment had a kappa value of 0.765 indicating a good correlation between the assessment and the final result ( Table 3). This difference between the external first assessment and the second assessment was highly significant $(\mathrm{p}<0.001)$.

\section{Changes to treatment after second assessment}

Overall, a total of $97 / 374$ cases (26\%) were reclassified after the second assessment.

In 71/97 cases (74\%) there was a reclassification from BI-RADS 4 according to the first assessment to BI-RADS 3 in the second assessment, which turned out to be a correct diagnosis of findings in 68/71 of patients. Of these 68 patients, follow-up was indicated in 35 women, and the follow-up was uneventful. In 14 patients, the lesion was investigated at the patient's request using ultrasound-guided biopsy. In 19 cases with microcalcifications on mammography without a sonographic correlate, the lesion was investigated after consultation with the patient and the referring
Table 1 Correlation between BI-RADS classification made at the first and second assessment with histology.

\begin{tabular}{|c|c|c|}
\hline & $\begin{array}{l}\text { First assessment } \\
\text { benign/malignant }\end{array}$ & $\begin{array}{l}\text { Second assessment } \\
\text { benign/malignant }\end{array}$ \\
\hline BI-RADS 1,2 & $11 / 0$ & $11 / 0$ \\
\hline BI-RADS 3 & $35 / 20$ & $97 / 3$ \\
\hline BI-RADS 4,5 & $100 / 208$ & $38 / 225$ \\
\hline
\end{tabular}

Table 2 Distribution of false-negative and positive findings (FN/FP) depending on the assessment. Two of 374 cases were normal (BI-RADS 1). The relative and the absolute number of false-negative and false-positive findings for the individual assessments and for the total number of patients are shown.

\begin{tabular}{|c|c|c|c|c|}
\hline & FN & FP & FN & FP \\
\hline & $\begin{array}{l}\text { First } \\
\text { diagnosis }\end{array}$ & $\begin{array}{l}\text { First } \\
\text { diagnosis }\end{array}$ & $\begin{array}{l}\text { Second } \\
\text { diagnosis }\end{array}$ & $\begin{array}{l}\text { Second } \\
\text { diagnosis }\end{array}$ \\
\hline $\begin{array}{l}\text { Focal } \\
\text { findings }\end{array}$ & $\begin{array}{l}4.5 \% \\
(11 / 245)\end{array}$ & $\begin{array}{l}19 \% \\
(46 / 245)\end{array}$ & $\begin{array}{l}0 \% \\
(0 / 245)\end{array}$ & $\begin{array}{l}8.6 \% \\
(21 / 245)\end{array}$ \\
\hline $\begin{array}{l}\text { Microcalci- } \\
\text { fications }\end{array}$ & $\begin{array}{l}6.4 \% \\
(5 / 78)\end{array}$ & $\begin{array}{l}40 \% \\
(31 / 78)\end{array}$ & $\begin{array}{l}1.3 \% \\
(1 / 78)\end{array}$ & $\begin{array}{l}13 \% \\
(10 / 78)\end{array}$ \\
\hline Other $^{1}$ & $\begin{array}{l}9 \% \\
2 / 22\end{array}$ & $\begin{array}{l}64 \% \\
14 / 22\end{array}$ & $\begin{array}{l}0 \% \\
0 / 22\end{array}$ & $\begin{array}{l}13.6 \% \\
3 / 22\end{array}$ \\
\hline $\begin{array}{l}\text { Only } \\
\text { sonography² }\end{array}$ & $\begin{array}{l}7.4 \% \\
2 / 27\end{array}$ & $\begin{array}{l}33 \% \\
9 / 27\end{array}$ & $\begin{array}{l}7.4 \% \\
2 / 27\end{array}$ & $\begin{array}{l}14.8 \% \\
4 / 27\end{array}$ \\
\hline Total & $\begin{array}{l}5.4 \% \\
20 / 372\end{array}$ & $\begin{array}{l}26.9 \% \\
100 / 372\end{array}$ & $\begin{array}{l}0.8 \% \\
3 / 372\end{array}$ & $\begin{array}{l}10.2 \% \\
38 / 372\end{array}$ \\
\hline
\end{tabular}

1 Asymmetries or architectural distortion on mammography and galactography images (2 cases).

2 Findings only visible on sonography.

Table 3 Sensitivity, specificity and correlation of assessment with histology (kappa value).

\begin{tabular}{|llll} 
& Sensitivity & Specificity & Kappa value \\
\hline First assessment & $91 \%$ & $32 \%$ & 0.263 \\
\hline Second assessment & $99 \%$ & $74 \%$ & 0.765
\end{tabular}


physician by surgical intervention at the express wish of the patient; in all cases the findings were benign.

In 3 cases, the classification as benign made at the second assessment turned out to be false-negative ( $\bullet$ Table 1 ). All 3 findings were $<1 \mathrm{~cm}$ at the final diagnosis. In one patient, the mammogram showed demonstrable microcalcifications. At operation, a ductal carcinoma in situ (Van Nuys group II) with a diameter of $9 \mathrm{~mm}$ was found. In the two other cases, a smooth, well circumscribed, hypoechoic mass was found on sonography which was also noted as a smooth circumscribed focus on mammography and classified as BI-RADS 3.

Histological investigation found an 11-mm lobular breast cancer and an invasive tubular breast cancer with a diameter of $10 \mathrm{~mm}$. These 2 patients underwent surgery between 1 and 5 months after presenting for a second assessment.

In 26/97 (27\%) patients, suspicious findings requiring histological clarification were found at the second assessment; these findings had been classified as BI-RADS 3 at the external assessment. 20 of the reclassifications undertaken at the second assessment were true-positive and were ultimately treated by surgical intervention.

Of the findings reclassified as suspicious in the second assessment by the radiology outpatient department, six reclassifications turned out to be false-positive. In 2 cases the findings consisted of grouped microcalcifications, and the final diagnosis was made at surgery. In 2 cases galactography findings were abnormal: in 1 patient there was no histological correlate at surgery and in the other patient a milk-duct papilloma was found at surgery. In the last 2 cases the histological findings obtained with punch biopsy were normal.

In summary, in 88 cases ( $91 \%$ ) out of a total of 97 women reclassified at the second assessment, the change of BI-RADS classification in the second assessment turned out to be correct. Thus, almost one in four women (88/374: $24 \%$ ) of the investigated collective profited from having a second assessment.

Forty-nine women were spared an unnecessary surgical intervention, and in 20 women a malignancy was only correctly diagnosed at the second assessment.

Both sensitivity and, in particular, specificity were increased by the second assessment (O Table $\mathbf{3}$ ).

\section{Discussion}

$\nabla$

The certification of breast centres in accordance with the guidelines of the German Cancer Society and the German Society of Senology includes proposals for an interdisciplinary cooperation at pre-therapeutic case conferences [16]. In our clinic, all patients referred for breast surgery first present to the Radiology Department for an assessment of external findings, and the results are then discussed with the gynaecologists. In addition patients can always present directly or be referred by their physician to the outpatient department of the radiology policlinic or the medical healthcare centre.

Our study showed that referred patients benefited from a second assessment done preoperatively at the breast centre. The second assessment increased the sensitivity from 91 to $99 \%$ and increased the specificity from 32 to $74 \% .49$ women were spared an unnecessary operation with this second assessment. A malignant lesion was only diagnosed at the second assessment in 20 women, allowing early therapeutic measures to be taken. Almost one in four women benefited from a second assessment made in the breast centre. The number of patients who might have been spared a surgical intervention could have probably even been increased; however, it must be remembered that the indication for surgery had often already been made by the time patients were referred to the breast centre, and that some patients, surgeons, and referring physicians also preferred complete surgical removal of lesions.

The study which best compares with our study is a retrospective study done at the university clinic of Mainz in 2006 [17]. Here too, the benefit of a second assessment in a breast centre was investigated in 236 patients. What is notable is the significant increase in specificity through the second assessment, from $30 \%$ in the primary assessment to $78 \%$, which is almost identical to our data. In the study of 2006, the sensitivity of the first assessment was much lower (81\%) and, as in our study, could be increased to $96 \%$. However, it should be noted that in the Mainz study, 49 women underwent additional breast MRT in the breast centre, which involved additional costs, and which served in one third of cases to reconfirm the reclassification of findings as lesions which did not require histological workup.

A study in 2007 of the pilot project "Quality Assurance in Breast Diagnostics" in Schleswig-Holstein with 59514 patients was far more comprehensive [18]. These investigations, done outside regular breast cancer screening programmes, included an independent double assessment as a standard part of diagnostic mammography. If the second opinion diverged or when abnormalities (BI-RADS 4 und 5) were found, a third assessment was done by an independent breast centre or the patient was recalled for a diagnostic workup. Their data showed a consensus between the first and second assessments in $78 \%$ of cases, a figure which is almost identical to the one in our study (74\%). Women also benefited from having a second assessment in this project. The number of verified breast cancers in the investigated region increased by $10 \%$, and there was a distinct shift to lower tumour stages (Tis and T1), which accounted for $63 \%$ of the collective compared to a figure of only $49 \%$ for the rest of Schleswig-Holstein. In our study, the figure for lower stage tumours was $64 \%$ and thus comparable with the figures of the Schleswig-Holstein study. An increase in verifiable cancers by $8 \%$ in our collective after the second assessment also showed a diagnostic benefit for patients comparable to that of the Schleswig-Holstein study.

The advantages associated with a second assessment must be seen alongside potential downsides for patients such as falsepositive findings and, more serious for patients, false-negative findings.

In their study, Pacher et al. analysed the importance of a second assessment in diagnostic mammography and sonography. In 57 cases classified as BI-RADS 4 and 5, the findings differed in 16 cases, 5 of which were correctly reclassified at the second assessment from BI-RADS 3 to 4 . However, 5 patients were incorrectly reclassified from benign to malignant at the second assessment, while data on the remaining patients is lacking [19].

The percentage of false-positive findings in our study after the second assessment was low, amounting to only $10 \%$ of all assessed cases. After the first assessment, histological workup was unnecessarily indicated for $27 \%$ of women, that is, for almost 1 in 3 patients. It should be noted, however, that the use of punch biopsy, particularly in certified breast centres offers a further means of ascertaining the histological diagnosis and this was not used in the first assessment in our collective. The higher classification of a lesion as BI-RADS class 4 in a first assessment may 
represent a medico-legal safeguard and could be the possible cause behind the higher number of false-positive findings [20]. Three findings were falsely downgraded from BI-RADS 4 to 3 in the second assessment, 2 of which were cancers. However, surgery was performed in both cases within 5 months, so there was no significant delay in treatment. The Mainz study also reported 3 false-negative reclassifications. The authors rightly pointed out that such findings can never be totally excluded if the positive predictive value is significantly increased [17].

A limitation of our study is that the patients were a highly selected collective. All patients presented to us at their own request or at the recommendation of their referring physician. This collective therefore does not permit any generalised statement to be made regarding the quality of first assessment per se. It should also be noted that the improved assessment of findings at the second assessment was assisted by a knowledge of the previous findings [21]. Similarly, the pre-selection of patients through referring gynaecologists when findings were unclear or appeared clinically abnormal had an influence on the significance of the second assessment. The low specificity of the first assessment was doubtlessly also due to medico-legal reasons, which were more likely to lead to a cautious approach and quicker recommendations for histological workup. The European Society of Mastology (EUSOMA) estimates that 1500 unclear cases need to be investigated for every 150 operated breast cancers [22].

The studies cited above on the effect of second assessments in diagnostic mammography in other independent regions with rural and urban referring structures show, in all essential points, strikingly similar results, so that we can conjecture that similar effects would be found after second assessments for other certified breast centres.

In summary, the results of our study show that second assessments undertaken by breast centres offer clear benefits. Patients are spared unnecessary interventions and the rate of proven malignancies can additionally be increased.

\section{Conflict of Interest}

$\nabla$

None.

\section{References}

1 Thurfjell EL, Lernevall KA, Taube AS. Benefit of independent double reading in a population-based mammography screening program. Radiology 1994; 191: 241-244

2 Antinnen I, Pamillo M, Soiva $M$ et al. Double reading of mammography screening films - one radiologist or two? Clinical Radiology 1993; 48: 414-421

3 Perry NM; EUSOMA Working Party. Quality assurance in the diagnosis of breast disease. EUSOMA Working Party. Eur J Cancer 2001; 37 : 159-172

4 Schulz KD, Albert US, eds. Stufe-3-Leitlinie Brustkrebs-Früherkennung in Deutschland. München: W. Zuckschwerdt Verlag; 2003

5 Kreienberg R, Albert S, Follmann M et al., eds. Stufe-3-Leitlinie Diagnostik, Therapie und Nachsorge des Mammakarzinoms der Frau. Deutsche Krebsgesellschaft e.V.; 2012

6 Duda VF. S1-Leitlinie Mammasonographie. Frankfurt: Deutsche Gesellschaft für Senologie; 2002

7 Pfarl G, Helbich TH. Breast Imaging Reporting and Data System (BIRADS $^{\mathrm{TM}}$ ) - Deutsche Version. Fortschr Röntgenstr 2002; 174: 921-926

8 Fischer U; Deutsche Röntgengesellschaft, eds. Mammographiebefundung nach BI-RADS. Illustrierte Anleitung zur einheitlichen Befunderstellung. Stuttgart: Thieme; 2003

9 Osuch JR, Anthony M, Bassett LW et al. A proposal for a national mammography database: content, purpose, and value. Am J Roentgenol 1995; 164: 1329-1334

10 Taplin ST, Ichikawa LE, Kerlikowske Ket al. Concordance of breast imaging reporting and data system assessments and management recommendations in screening mammography. Radiology 2002; 222: 529535

11 Kolberg H-C, Lüftner D, Lux MP et al. Breast cancer 2012 - new aspects. Geburtsh Frauenheilk 2012; 72: 602-615

12 Orel GB, Kay N, Reynolds C et al. BI-RADS Categorization as a predictor of malignancy. Radiology 1999; 211: 845-850

13 Liberman L, Abramson AF, Glassmann JR et al. The breast imaging reporting and data system: Positive predictive value of mammographic features and final assessment categories. AJR 1998; 171: 35-40

14 Cohen JA. A coefficient of agreement for nominal scales. Educ Psychol Measurement 1960; 20: 37-46

15 Landis JR, Koch GG. The measurement of observer agreement for categorical data. Biometrics 1977; 33: 159-174

16 Deutsche Krebsgesellschaft und Deutsche Gesellschaft für Senologie. Erhebungsbogen für Brustzentren. 2010. www.senologie.org

17 Teifke A, Vomweg WV, Schmidt M et al. Mammadiagnostische Zweitbefundung in der Klinik. Fortschr Röntgenstr 2006; 178: 330-336

18 Katalinic A, Bartel C, Raspe $H$ et al. Beyond mammography screening: quality asssurance in breast cancer diagnosis. Br J Cancer 2007; 96: 157-161

19 Pacher B, Tscherney R, Litmann-Rowenta B et al. Konsensuelles Zweitbefunden von Mammographien in der Praxis. Fortschr Röntgenstr 2004; 176: 1766-1769

20 Schulz-Wendtland R, Bani M, Lux MP et al. Pilot study on the detection of simulated lesions using a 2D and 3D digital full-field mammography system with a newly developed high resolution detector based on two shifts of a-Se. Geburtsh Frauenheilk 2012; 72: 408-411

21 Schulz-Wendtland R, Dilbat G, Bani M et al. Full field digital mammography (FFDM) versus CMOS technology versus tomosynthesis (DBT) which system increases the quality of intraoperative imaging? Geburtsh Frauenheilk 2012; 72: 532-538

22 Blamey R, Blichert-Toft M, Cataliotti L et al. Position paper EUSOMA. The requirements of a specialist breast unit. Eur J Cancer 2000; 36: 22882293

Deutschsprachige Zusatzinformationen online abrufbar unter: www.thieme-connect.de/ejournals/toc/gebfra. 